Western University

Scholarship@Western

Aboriginal Policy Research Consortium International (APRCi)

4-2009

\title{
Research and Indigenous participation: critical reflexive methods
}

Ruth Nicholis

Follow this and additional works at: https://ir.lib.uwo.ca/aprci

Part of the Community-Based Research Commons, and the Intellectual Property Law Commons

Citation of this paper:

Nicholis, Ruth, "Research and Indigenous participation: critical reflexive methods" (2009). Aboriginal Policy Research Consortium International (APRCi). 166.

https://ir.lib.uwo.ca/aprci/166 
This article was downloaded by: [University of Western Ontario]

On: 18 November 2012, At: 07:07

Publisher: Routledge

Informa Ltd Registered in England and Wales Registered Number: 1072954 Registered

office: Mortimer House, 37-41 Mortimer Street, London W1T 3J H, UK

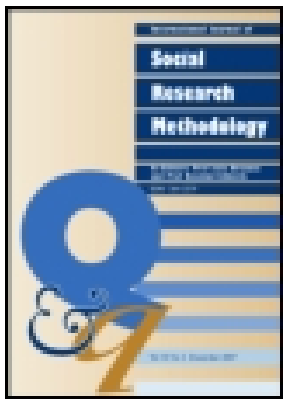

\section{International J ournal of Social Research Methodology}

Publication details, including instructions for authors and subscription information:

http:// www.tandfonline.com/loi/ tsrm20

\section{Research and Indigenous participation: critical reflexive methods}

Ruth Nicholls ${ }^{a}$

a Social J ustice and Social Change Research Centre, University of Western Sydney, Australia

Version of record first published: 03 Mar 2009.

To cite this article: Ruth Nicholls (2009): Research and Indigenous participation: critical reflexive methods, International J ournal of Social Research Methodology, 12:2, 117-126

To link to this article: http:// dx.doi.org/ 10.1080/ 13645570902727698

\section{PLEASE SCROLL DOWN FOR ARTICLE}

Full terms and conditions of use: http://www.tandfonline.com/page/terms-andconditions

This article may be used for research, teaching, and private study purposes. Any substantial or systematic reproduction, redistribution, reselling, loan, sub-licensing, systematic supply, or distribution in any form to anyone is expressly forbidden.

The publisher does not give any warranty express or implied or make any representation that the contents will be complete or accurate or up to date. The accuracy of any instructions, formulae, and drug doses should be independently verified with primary sources. The publisher shall not be liable for any loss, actions, claims, proceedings, demand, or costs or damages whatsoever or howsoever caused arising directly or indirectly in connection with or arising out of the use of this material. 


\title{
Research and Indigenous participation: critical reflexive methods
}

\author{
Ruth Nicholls* \\ Social Justice and Social Change Research Centre, University of Western Sydney, Australia
}

(Received 2 May 2008; final version received 28 November 2008)

\begin{abstract}
In response to the theories of empowerment and social justice, research involving Indigenous peoples often demands participatory and collaborative methodologies. Consequently, researchers need to engage with reflexive evaluation of collective and negotiated design, data collection and data analysis to consider inter-personal and collective dynamics during the research process. What this means for those attempting counter-colonial research is that we cannot rely on a singular application of reflexivity to situate knowledge. Additional political and relational layers of reflexivity are essential to critically evaluate empowerment and participation by working 'the spaces between' through reflection about collaboration. By exploring 'relationality' as a methodology, this paper discusses three layers of reflexivity (self-reflexivity, inter-personal reflexivity and collective reflexivity). This reflexive work entails resisting essentialist positions while also recognising difference within a collective. The result is the ability to see that the Self-Other hyphen both connects and distinguishes between us, in processes of collaborative counter-colonial research.
\end{abstract}

Keywords: indigenous; participatory research; reflexivity

\section{Introduction}

No matter what discipline you work in, the counter-colonial voices of Indigenous peoples are now well-articulated in ethics and methods literature. For example, Linda Tuhiwai Smith's Decolonizing Methodologies: Research and Indigenous Peoples (1999) is a seminal work for any researcher seeking to actively recognise the injustices of the past and present research practices. Many researchers (across disciplines ranging from human geography to social epidemiology) are heeding this call, by moving to identify with social justice methodology that seeks to alter power relations between participants and researchers (Potts \& Brown, 2005). There is of course divergence amongst Indigenous standpoints regarding the probity of non-Indigenous involvement in research with and for Indigenous peoples. In this paper, I am not seeking to assert a non-Indigenous right to continue placing 'Others' under the research microscope. Instead, I am interested to explore the capacity to which a non-Indigenous researcher can engage with the challenges that the counter-colonial research methods present. In this respect, I am attentive to integrity in social justice methodology working 'the spaces between' through reflection about collaboration and participation in research.

To attend to these spaces, I will critically consider concepts such as 'participation' and 'empowerment'. I do this to carefully consider praxis, rather than reject these

*Email: r.nicholls@uws.edu.au 
concepts. Following this, I outline some reflexive methods I have used in collaborative research with members of an Aboriginal community organisation located on the fringe of Sydney, Australia. Our research has focused on aspects of community development and my involvement as a researcher has been framed as a volunteer contributing to capacity building through sharing skills and collaboratively undertaking research which is useful to the organisation for the delivery of community development activities. In this way, the methodology to which I am referring is not necessarily discipline specific, although it is most obviously positioned within frames of social justice inquiry focusing on community, development, collaborative methods and cross-cultural positionality.

\section{The fluid and the fixed: alterity and essentialisms}

Within this paper, I am interested in considering ethical demands at the personal/ political level (Mohan, 1999) when attempting to undertake collaborative, participatory, counter-colonial research. To do this, I draw on the idea of researcher subjectivity being fluid rather than fixed, although located in a binary of colonial relations (Bhattacharya, 2007). This incorporates Narayan's (1998) argument against cultural and gender essentialism by recognising that such essentialisms are 'neat packages' derivative of the colonial rationale of invasion and imperialism.

What postcolonial feminists need to do is not endorse 'cultural relativism' but to resist various forms of cultural essentialism, including relativist versions ... by pointing to the internal plurality, dissention and contestation over values and ongoing changes in practices in virtually all communities. (Narayan, 1998, p. 46).

This demands a separation of discursive construction of subjectivity from structural location (Fawcett \& Hearn, 2004, p. 211), exemplified for example in the development of a pro-Feminist male standpoint (Pease, 2000). Similarly, Bishop argues that discursive repositioning 'challenges the essentialising dichotomization of the insider/ outsider debate' (Bishop, 2005, p. 115), which otherwise 'assume[s] a homogeneity that is far from the reality of the diversity and complexity' (Bishop, 2005, p. 111) of what all participants in a collaboration have to offer. This also applies to the differences amongst forms of collaborative arrangements (Jones with Jenkins, 2008, p. 472).

Injunctions for participation demand methods that reify local and lived knowledge (Mohan, 1999, p. 42), and focus on praxis (Lather, 1988) to address interests and concerns of the participants. This requires critical work that incorporates reflexivity between peers (Siltanen, Willis, \& Scobie, 2007), acknowledging difference within a collective (McCorkel \& Myers, 2003), and critically framing alterity while not creating rigid definitions of research process goals or participant homogeneity (Fawcett \& Hearn, 2004, p. 209).

What this means for those attempting counter-colonial research is that we cannot rely on a 'first person' application of reflexivity to situate knowledge (Rose, 1997). Researchers need to engage with reflexive evaluation of collective and negotiated design, data collection and data analysis to consider the interpersonal and collective dynamics during the research process, and any effects that the research may potentially have into the future. Additional political and relational layers of reflexivity are essential for a researcher to critically evaluate empowerment and participation in a counter-colonial context. This enables rigorous evaluation of the 'messiness' that emerges in collaborative efforts: such as revelations of irreconcilable alterity (Jones 
with Jenkins, 2008, p. 475; Kowal, 2006); and an ability to acknowledge 'internal conflicts and contradictions' (Fawcett \& Hearn, 2004, p. 211).

I do not seek to define Indigeneity or non-Indigeneity for the purposes of this argument (cf. Niezen, 2003). Instead, I recognise the complexity and contestations that reflect the many different peoples who identify as 'Indigenous' and indeed, the researchers who in turn recognise their alterity in relation to participants (Fawcett \& Hearn, 2004). What recognition of alterity often results in is a turn towards 'participation' and 'empowerment' as a way of countering the situated power/knowledge of the researcher. Researchers must exercise caution in working the hyphen. The goal of collaborative work should not be to 'dissolve/consume/soften/erase' difference (Jones with Jenkins, 2008, p. 475), for 'indigenous peoples - as a matter of political, practical and identity survival as indigenous peoples - insist on a profound difference at the Self-Other border. The hyphen is non-negotiable' (Jones with Jenkins, 2008, p. 475).

\section{Empowerment and participation}

Empowerment is often viewed as an organising principle for social change (Baistow, 1994). But what forms of situated knowledge, influenced by material and social locations, might suggest who is in need of transformation? Researchers might consider Indigenous participants as candidates for empowerment because they 'have been systematically deprived of power ... and need to reclaim it as a (citizen's) right' (Baistow, 1994, p. 37).

Solutions to health inequities now commonly incorporate participation and empowerment. In Australia for example, Indigenous peoples' health status is associated with lower life expectancy rates. This 'gap' stimulates policy responses to improve the health of population groups by increasing participation and empowerment in the delivery of services and research protocols (Kowal, Anderson, \& Bailie, 2005). The rights of Aboriginal and Torres Strait Islander peoples to be actively involved in research about their communities are statutory (National Health and Medical Research Council, 2003). Similarly, the World Health Organisation (WHO) principles for ethical research with Indigenous populations also direct research towards participation and collaboration (WHO, 2008).

In the 'normative' application of justice as fair and equal distribution of resources (Young, 2001), empowered participants within health delivery and research become evidence of the moral constitution of citizenry (Croft \& Beresford, 1992, p. 24), representing those who are willing to be transformed and to become empowered (Baistow, 1994, p. 37). This vision of participation is based upon methods that assume harmonious consensus (Mohan, 2001, p. 159), which suggests some murky power relations. As Henkel and Stirrat point out, 'the attempt to empower people through the projects envisaged and implemented by the practitioners of the new orthodoxy is always an attempt, however benevolent, to reshape the personhood of the participants' (2001, p. 182). Within this logic, there is a social justice imperative to make research participatory (Baistow, 1994, p. 40), partnered with a moral imperative for participants to be actively involved (Kothari, 2001, p. 148).

Bishop (2005, p. 121) asserts that empowerment cannot be stimulated from outside by means of material repositioning; it must be subjective and emergent from within 'a participatory mode of consciousness' (Heshusius, 1994). Participation through collaboration demands the researcher not to be in control of the research process (Sense, 2006). Ceding control can potentially be a very painful process for a researcher. It can 
result in disorientation of their vision of research, stress regarding contractual obligations with funding bodies and institutions to meet time lines and concrete objectives, countered also by inter-personal responsibilities and accountability to participants (Hill, 2004). The researcher may experience this as a form of pain and suffering or vulnerability (Kowal, 2006, p. 238). But this is also a requirement of proving commitment to anti-colonial research practice by a willingness to demonstrate methods which allow for negotiation. For example, Kowal observes an example of non-Indigenous health professionals submitting research for ethical review:

White antiracists must show how they changed their plans, bent to Indigenous desires, if they are to demonstrate their 'integrity'. In effect they must demonstrate the inverted power relations of postcolonial spaces. (2006, p. 248)

It is important to consider that the genesis of collaborative, participatory research was to destabilise the control of professionals and experts in their creation of knowledge about 'Others' (Mohan, 1999, p. 43). Participatory research produces various types of knowledge; experiential, fusing with theoretical to produce 'practical knowing' which is deemed to generate social transformation, often referred to as the 'action turn' (Chiu, 2006, p. 190). Literature describing modes of community-based participatory research often assert an implicit ethicality by virtue of inclusivity and democratisation of research (Boser, 2006). While recognising critiques of the 'authenticity' of collaboration (Byrne-Armstrong, 2001; Foley \& Valenzuela, 2005), the focus of this paper will now shift to understanding how Indigenous epistemologies and axiologies have informed undertaking participatory and collaborative research.

\section{Relationality as methodology}

There are many similarities that may be drawn with post-structural Feminist approaches which highlight connectedness (and disconnectedness) with research participants (McCorkel \& Myers, 2003, p. 204; Gibson-Graham, 1994) and the 'complex, shifting and dynamic' (McCorkel \& Myers, 2003, p. 223) shape of such relationships. What differs however is that 'Indigenous methodologies tend to approach cultural protocols, values and behaviours as an integral part of methodology' (Smith, 1999, p. 15). Relationality in this context is ontology, epistemology and axiology.

your methodology has to ask different questions: rather than asking about validity or reliability, you are asking how am I fulfilling my role in this relationship? ... This becomes my methodology, an Indigenous methodology, by looking at relational accountability or being accountable to all my relations. (Wilson, 2001, p. 177)

Researchers are expected to develop prevailing relationships with participants (Bishop, 2005, p. 117) on the terms of the local community (Bishop, 2005, p. 129). Maori researchers have outlined an epistemology through Kaupapa Maori which explains the cultural expectations of relating to participants, ethically and respectfully. The approach articulates a self-determined epistemology, rather than one which is controlled by a cultural outsider with the mission to 'empower' research participants (Bishop, 2005, p. 123). Smith's writings provide detail of culturally specific expectations, which provide clues for non-Indigenous researchers to consider how a community might judge them to be a trustworthy, 'good' person (Smith, 1999, pp. 119-120). 
Much of the focus of this approach is about relationality and conduct, and distinguishes between the development of rapport with participants and the development of trust (Bishop, 2005, pp. 111-112). The notion of rapport does not always incorporate critical ideas of responsibility to community participants (Oakley, 2003, pp. 245-247). The way in which rapport extends into trust and meaningful engagement is by the researcher proving themselves as willing to move into a liminal, in-between space, decentering themselves by challenging traditional notions of objective control between researchers and research participants. This process is how Heshusius suggests we begin 'describing ourselves and our work in ethical (and therefore participatory) terms' (1994, p. 20). Bishop recognises that there are some similarities between Kaupapa Maori and collaborative participatory methods, but develops more detail about the 'discursive positionings within the collective' (2005, p. 121); he goes on to elaborate that '[ $\mathrm{t}$ ]his emphasis on positionings within a group constituted as whanau [family] also addresses concerns about accountability, authority and control' (2005, p. 121). From this standpoint, 'while cross-cultural competency could be argued as a necessary condition for the researcher to engage in participatory research, it is not sufficient in itself to ensure empowerment of the other research participants' (Bishop \& Glynn, 1999, p. 178). Similarly, Nagar emphasises the researcher's need to reconceptualise their place within collaboration as 'a fissured space of fragile and fluid networks of connections and gaps' (2003, p. 359), for " "us" cannot stand in place of the hyphen; it can only name an always conditional relationship between' (Jones with Jenkins, 2008, p. 475).

\section{Multi-layered reflexivity}

Reflexive identification of the researcher's discursive position within a collaboration amongst a researcher and community-based knowers is to recognise that there are at least three layers of reflexivity required (Chiu, 2006, p. 191). This differs from literature regarding researchers using reflexivity in peer-based team work (Siltanen et al., 2007). The layers of reflexivity I consider as part of my methods are 'self-reflexivity', 'interpersonal reflexivity', and 'collective reflexivity', drawing particularly by the model outlined by Chiu (2006), though differing in theoretical analysis (she uses Bourdieu's concept of habitus, while I will situate each layer within the context of counter-colonialism). Another similar structure of 'first-, second-, third-person inquiry' is outlined by Reason and Bradbury (2008, p. 6), as a means for distinguishing between voice(s) and practice - however there is a different intention in this application.

The focus in this paper is to identify discursive positions within a collective, and to account for movement, fragility, fluidity and change within collaborative research relationships. By practising the three layers of reflexivity, there is an opportunity to reframe notions of justice, empowerment and participation within research as a paradigm of relationships that nurture self-determination, whereby 'the individual person is constituted through his or her communicative and interactive relations with others. The individual person acquires a sense of self from being recognized by others with whom he or she has relationships' (Young, 2004, p. 183).

\section{Transparent, self-reflexivity}

The first layer is self-reflexivity (1st person) which asks the researchers to identify what hidden assumptions may underpin their research. For example, what disciplinary theories structure the research proposal or funding which have enabled the research to 
proceed? Feminist researchers refer to this as 'reflexive transparency' (Oakley, 2003; Rose, 1997) and although it does not necessarily contribute to a broader agenda of social change evaluation within the research process, it does enable reconceptualised quality assessment (Lather, 2003). The researcher must be aware of the context of power and privilege in the research process, of what ideas were included and what ideas were excluded according to pre-determined elements brought by the skills or strengths of the researcher.

First person reflexivity also demands that the researcher consider the ways in which they write about collaborative research. There has been a noted tendency for researchers to 'hide' within collaborative texts (Pain, 2004, p. 658), and there is a danger that this 'systematically distorts the power positioning of all who participated in the research' (Chiu, 2006, p. 189). Others have noted the irrelevance that writing to academic audiences holds for community inquirers who are more interested in the practical outcomes of the research activity or in the production of material for use by the community involved (Nagar, 2003). It is therefore pivotal for the collaborative researcher to recognise their identity when presenting material intended for a variety of audiences. In case of this paper, I am writing for an academic audience about my attempt at discursive repositioning while collaborating with Indigenous co-inquirers. As such, this writing differs from other collaborative representations, where we have provided multi-vocal accounts of our research relationship.

Heshusius (1994) contends that it is possible to become over-concerned with the self, emphasising the distance between self and others as a result of efforts to manage subjectivity. In this way, 'the preoccupation with how to account for one's subjectivity can be seen as a subtle version of empiricist thought, in that it portrays the belief that one knows "how to handle things" (Hersusius, 1994, p. 16). This highlights the need for additional layers of reflexivity; not towards controlling collaboration, but as a gesture of attention and receptivity to the relational, the spaces in-between. Working reflexively in the inter-personal and collective layers reveals what connects those working in collaboration, just as self-reflexivity highlights the hyphen of difference between us, with all of its complexity and tensions (Jones with Jenkins, 2008, p. 473).

\section{Inter-personal reflexivity}

The second layer is relational-reflexivity (2nd person), which calls for an evaluation of interpersonal encounters and the researcher's ability to collaborate with others. As Feminist researchers have noted 'Reflexivity has mainly focused on examining the identities of the individual researcher rather than the ways in which those identities intersect with institutional, geopolitical and material aspects of their positionality' (Nagar, 2003, p. 356). Positionality enables the researcher to consider the terms of their inclusion within the collaboration by considering interpersonal encounters along the research journey, and the ability to collaborate (as opposed to lead, control or delegate). Kaupapa Maori demonstrates an intersection between what is deemed ethical behaviour by the community (as opposed to institutional or non-Indigenous determinants of ethical behaviour) and the necessity for the researcher to be self-aware of the process in which they are embedded (Bishop, 2005; Smith, 1999).

Within my research experience, community co-inquirers have communicated the idea of positionality as a fine balance of commitment to relationships and self-checking. 
Co-inquirers have not demanded that I deny my subjectivity of 'being' a researcher, but that I acknowledge such a role and then build relationships of trust in that acknowledgement. Our discussions evoke the partial knowledge I've gained, moving in and out of collaboration:

the more relationships that you build, the more quality that you're going to get outta your research. As long as you can be partial I suppose, and not have your whole heart and soul in with the people as well ... I dunno. I think you would really need to look at that, to step back from it sometimes maybe as a researcher. I think you get more quality from us, because we've built a relationship for nearly two years. (personal communication, 18 September 2007)

Recognition of relationships is exemplified in the distinction made between traditional modes of interviewing research subjects in contrast to developing 'authentic rapport' with research participants (Oakley, 2003). Extending this into an agenda of collaborative inquiry demands complex and careful negotiation to include community-determined inquiry (Smith, 1999, p. 137).

\section{Collective reflexivity and catalytic validity}

The third layer of reflexivity is where the biggest claims about social change are made in participatory action methodologies. This third layer demands the question of asking about the process of how the collaboration determined the frames of inquiry. It also asks what were the terms of participation, who participated or did not... and what effects did this have on the outcome of social change and practical knowing for the community participants. As another community co-inquirer shares with me:

I think part of it is that, some researchers probably don't necessarily have the ability to empathise very well with other people and empathy, is an important part of it ... I don't think it has to be necessarily sympathetic, but I think if you can empathise with some of the things that might have happened to people, that happened in the past, well that's important. I haven't had a lot experience with this sort of research, but I would imagine it's a fairly important part. Understanding people a little bit, and maybe knowing when to take a step back too, or understanding their reactions - if they're angry reactions, figuring out why, and whether you need to rethink how you do things. (personal communication, 30 November 2007)

Building upon a reflexive determination of positionality, this layer questions the idea of an all-knowing, all-seeing researcher, and connects with Patti Lather's (2003, p. 189) discussion of construct validity (was the theory underpinning the research actually relevant to findings; and in this case, 'practical knowledge'?) and face validity (were the findings analysed by the participants in the research as well as the researcher?).

Moreover, this layer of reflexivity calls for discussion amongst collaborating participants about the effects of taking part in research, to reflect together about whether participating was transformative, affirming, cathartic or empowering. Carter, Jordens, McGrath, and Little (2008) have undertaken longitudinal empirical research into the social processes of research participation. By coding interview data under a rubric of 'participating in research', Carter et al. (2008) have identified several domains of participation which shed light onto why people choose to participate, and 
also why people choose to disengage from the research experience. Most ethics review processes assume that research participants are at risk of emotional disturbance through participation, and protocols of protecting the well-being of participants must be set in place (such as highlighting the participant's right to exit research at any stage, and the availability of counselling services for participants if required). In contrast to this assumption, Carter et al.'s research has found that it was the participants having undergone an ontological and epistemic experience of reconstituting knowledge about themselves through involvement in research. Participants chose to exit the research process once this process of affirmation or catharsis reached saturation point. This is similar to earlier Feminist reflexive work that notes participants found the interview experience cathartic (England, 1994, p. 85).

Another approach for gleaning the experience of research for the participant is the idea that interviews may be epistemic (Brinkmann, 2007). This supposition, inspired by Socratic dialogue endeavours 'to move conversation partners from doxa to episteme (i.e. from a state of being simply opinionated to being capable of questioning and justifying what they believe is the case' (Brinkmann, 2007, p. 1117). Brinkmann argues that 'The conversation partners were thus positioned as responsible citizens, accountable to each other ... and the topic would therefore not be the narrative of the individual's life or his or her experiences but rather people's epistemic practices of justification' (2007, p. 1128). This provides clues to the establishment of ethical relationships which simultaneously seek to divulge a personal commitment and openness from the researcher while also operating within the rubric of a research relationship in a counter-colonial context. That the process entails finding 'a "common" understanding [which] does not imply fixity or comprehensiveness' (Siltanen et al., 2007, p. 49) enables some integrity in maintaining fluidity in the construction of subjectivities within the collaboration.

\section{Conclusion}

'Collective-reflexivity' seeks to articulate not only contextual change of action outcomes from the research (such as the procedural accounts of evaluation and output in the form of 'lessons learned') but extends into a domain of 'catalytic validity' (Lather, 2003, p. 191). The suggested reflexive process of collaborative 'sensemaking' is therefore a theoretically consistent tool within participatory methodology. However this third layer of reflexivity also demands that the researcher understand a shift in their positionality. This shift entails simultaneously being receptive to new cultural domains of understanding and attempting to maintain space for this throughout the entire research process by ceding researcher control beyond the initial phase of negotiation, and extending participation into data collection, analysis and distribution.

With this in mind, it is worth considering that gestures of inclusion require decentering: 'being open and susceptible ... learning from difference rather than learning about the Other' (Jones with Jenkins, 2008, p. 480). Whether it is possible to apply the three layers of reflexivity described in this paper equally and at all times is yet to be determined. From my experience, these movements and shifts are best considered as complex, unstable positions. Perhaps then, attention to the three layers of reflexivity is like juggling: requiring concentration, movement, balance and coordination. Juggling is resisting essentialist positions while also recognising difference. This is the ability to see that the hyphen both connects and separates us when we undertake collaborative counter-colonial research. 


\section{Acknowledgements}

I would like to acknowledge the Darug and Gundungurra Peoples as the traditional custodians of the nations in which I live and work. Thanks to community co-inquirers for your sage contributions. Thank you to all who have taken time to review this paper.

\section{Notes on contributors}

Ruth Nicholls is a PhD Candidate at the Social Justice and Social Change Research Centre of the University of Western Sydney. Her doctoral thesis explores ethics and methodology based on a case study of participatory action research with a community controlled Aboriginal organisation in Western Sydney.

\section{References}

Baistow, K. (1994). Liberation and regulation? Some paradoxes of empowerment. Critical Social Policy, 14, 34-46.

Bhattacharya, K. (2007). Consenting to the consent form: What are the fixed and fluid understandings between the researcher and the researched? Qualitative Inquiry, 13(8), 1095-1115.

Bishop, R. (2005). Freeing ourselves from neocolonial domination in research. In N.K. Denzin \& Y.S. Lincoln (Eds.), The handbook of qualitative research (3rd ed., pp. 109-138). Thousand Oaks, CA: Sage.

Bishop, R., \& Glynn, T. (1999). Researching in Maori contexts: An interpretation of participatory consciousness. Intercultural Studies, 20(2), 167-182.

Boser, S. (2006). Ethics and power in community-campus partnerships for research. Action Research, 4(1), 9-21.

Brinkmann, S. (2007). Could interviews be epistemic? An alternative to qualitative opinion polling. Qualitative Inquiry, 13(8), 1116-1138.

Byrne-Armstrong, H. (2001). Whose show is it? The contradictions of collaboration. In H. Byrne-Armstrong, J. Higgs, \& D. Horsfall (Eds.), Critical moments in qualitative research (pp. 106-114). Melbourne: Butterworth Heinemann.

Carter, S., Jordens, C., McGrath, C., \& Little, M. (2008). You have to make something of all that rubbish, do you? An empirical investigation of the social process of qualitative research. Qualitative Health Research, 18, 1264-1276.

Chiu, L.F. (2006). Critical reflection: More than nuts and bolts. Action Research, 4(2), 183-203.

Croft, S., \& Beresford, P. (1992). The politics of participation. Critical Social Policy, 12, 20-44.

England, K.V.L. (1994). Getting personal: Reflexivity, positionality, and feminist research. Professional Geographer, 46(1), 80-89.

Fawcett, B., \& Hearn, J. (2004). Researching others: Epistemology, experience, standpoints and participation. International Journal of Social Research Methodology, 7(3), 201-218.

Foley, D., \& Valenzuela, A. (2005). Critical ethnography: The politics of collaboration. In N.K. Denzin \& Y.S. Lincoln (Eds.), The handbook of qualitative research (3rd ed., pp. 217-234). Thousand Oaks, CA: Sage.

Gibson-Graham, J.K. (1994). 'Stuffed if I know!': Reflections on post-modern feminist social research. Gender, Place and Culture, 1(2), 205-224.

Henkel, H., \& Stirrat, R. (2001). Participation as spiritual duty: Empowerment as secular subjection. In B. Cooke \& U. Kothari (Eds.), Participation: The new tyranny? (pp. 168-184). New York: Zed Books.

Heshusius, L. (1994). Freeing ourselves from objectivity: Managing subjectivity or turning toward a participatory mode of consciousness. Educational Researcher, 23(3), 15-22.

Hill, S. (2004). Doing collaborative research: Doing what feels right and makes sense. International Journal of Social Research Methodology, 7(2), 109-126.

Jones, A., with Jenkins, K. (2008). Rethinking collaboration: Working the indigene-colonizer hyphen. In N.K. Denzin, Y.S. Lincoln, \& L.T. Smith (Eds.), Handbook of critical and indigenous methodologies (pp. 471-486). Los Angeles, CA: Sage.

Kothari, U. (2001). Power, knowledge and social control in participatory development. In B. Cooke \& U. Kothari (Eds.), Participation: The new tyranny? (pp. 139-152). New York: Zed Books. 
Kowal, E. (2006). The proximate advocate: Improving indigenous health on the postcolonial frontier. Unpublished doctoral thesis. Melbourne: Department of Public Health, University of Melbourne.

Kowal, E., Anderson, I., \& Bailie, R. (2005). Moving beyond good intentions: Indigenous participation in Aboriginal and Torres Strait Islander health research. Australian and New Zealand Journal of Public Health, 29(5), 468-470.

Lather, P. (1988). Feminist perspectives on empowering research methodologies. Women's Studies International Forum, 11(6), 569-581.

Lather, P. (2003). Issues of validity in openly ideological research: Between a rock and a soft place. In Y.S. Lincoln \& N.K. Denzin (Eds.), Turning points in qualitative research: Tying knots in a handkerchief (pp. 185-215). Walnut Creek, CA: AltaMira Press.

McCorkel, J.A., \& Myers, K. (2003). What difference does difference make? Position and privilege in the field. Qualitative Sociology, 26(2), 199-231.

Mohan, G. (1999). Not so distant, not so strange: The personal and the political in participatory research. Ethics, Place and Environment, 2(1), 41-54.

Mohan, G. (2001). Beyond participation: Strategies for deeper empowerment. In B. Cooke \& U. Kothari (Eds.), Participation: The new tyranny? (pp. 153-167). New York: Zed Books.

Nagar, R. (2003). Collaboration across borders: Moving beyond positionality. Singapore Journal of Tropical Geography, 24(3), 356-372.

Narayan, U. (1998). Essence of culture and a sense of history: Feminist critique of cultural essentialism. Hypatia (Border Crossings: Multicultural and Postcolonial Feminist Challenges to Philosophy, part 1), 13(2), 86-107.

National Health and Medical Research Council. (2003). Values and ethics: Guidelines for ethical conduct in Aboriginal and Torres Strait Islander health research. Canberra: Commonwealth of Australia.

Niezen, R. (2003). The origins of indigenism: Human rights and the politics of identity. Berkeley, CA: University of California Press.

Oakley, A. (2003). Interviewing women: A contradiction in terms. In Y.S. Lincoln \& N.K. Denzin (Eds.), Turning points in qualitative research: Tying knots in a handkerchief (pp. 243-263). Walnut Creek, CA: AltaMira Press.

Pain, R. (2004). Social geography: Participatory research. Progress in Human Geography, $28(5), 652-663$.

Pease, B. (2000). Recreating men: Postmodern masculinity politics. London: Sage.

Potts, K., \& Brown, L. (2005). Becoming an anti-oppressive researcher. In L. Brown \& S. Strega (Eds.), Research as resistance: Critical, indigenous, and anti-oppressive approaches (pp. 255-285). Toronto: Canadian Scholars' Press.

Reason, P., \& Bradbury, H. (2008). The Sage handbook of action research: Participative inquiry and practice. Los Angeles, CA: Sage.

Rose, G. (1997). Situating knowledges: Positionality, reflexivities and other tactics. Progress in Human Geography, 21(3), 305-320.

Sense, A. (2006). Driving the bus from the rear passenger seat: Control dilemmas of participative action research. International Journal of Social Research Methodology, 9(1), 1-13.

Siltanen, J., Willis, A., \& Scobie, W. (2007). Separately together: Working reflexively as a team. International Journal of Social Research Methodology, 11(1), 45-61.

Smith, L.T. (1999). Decolonizing methodologies: Research and indigenous peoples. Dunedin: Zed Books.

WHO. (2008). Indigenous peoples and participatory health research. Retrieved May 1, 2008, from http://www.who.int/ethics/indigenous_peoples/en/print.html

Wilson, S. (2001). What is an indigenous research methodology? Canadian Journal of Native Education, 25(2), 175-179.

Young, I.M. (2001). Equality of whom? Social groups and judgments of injustice. Journal of Political Philosophy, 9(1), 1-18.

Young, I.M. (2004). Two concepts of self-determination. In S. May, T. Modood, \& J. Squires (Eds.), Ethnicity, nationalism and minority rights (pp. 176-195). Cambridge: Cambridge University Press. 